\title{
JURNAL REDOKS
}

Pelindung

Muhammad Firdaus,S.T,M.T

(Dekan Fakultas Teknik Universitas PGRI Palembang)

\author{
Pengarah \\ Ir.M. Saleh Al Amin,M.T (Wakil Dekan I) \\ Adiguna,S.T,M.Si ( Wakil Dekan II) \\ Aan Sefentry,S.T,M.T ( Wakil Dekan III) \\ Pimpinan Editorial \\ Husnah ,S.T,M.T \\ Dewan Editorial \\ Ir.Muhammad Bakrie,M.T \\ Muhrinsyah Fatimura,S.T,M.T \\ Rully Masriatini,S.T,M.T \\ Nurlela,S.T,M.T \\ Marlina,S.T,M.T \\ Reno Fitrianti,S.T,M.Si \\ Andriadoris Maharanti,S.T,M.T \\ Ir.Agus Wahyudi.M.M
}

\section{Mitra Bestari}

Dr.Erfina Oktariani,S.T,M.T ( STMI Kementerian Perindustrian RI)

Dr.Rer.nat. Risfidian Mohadi, S.Si., M.Si (Universitas Sriwijaya).

Dr. Eko Ariyanto, M.Eng, Chem (Universitas Muhamadiyah Palembang)

Daisy Ade Riany Diem, ST., MT. (Sekolah Tinggi Teknologi Wastukancana)

\section{Staff Editor}

Endang Kurniawan,S.T

Yuni Rosiati,S.T

\section{Alamat Redaksi :}

Program Studi Teknik Kimia Universitas PGRI Palembang

Jalan Jend. A. Yani Lorong Gotong Royong 9/10 Ulu Palembang Sumatera Selatan

Telp. 0711-510043 Fax. 0711-514782 e-mail : tekim.upgri@gmail.com 


\section{JURNAL REDOKS}

Volume 1, Nomor 2, Juli - Desember 2016

\section{DAFTAR ISI}

Artikel Penelitian

Halaman

1. Pengolahan Air Limbah Pewarna Sintetis Untuk Menurunkan Kadar COD Dan Warna Dengan Metode Adsorpsi. (Nurlela) .................................................. 1-5

2. Penurunan Kadar Fenol Dalam Limbah Cair Industri Tenun Songket Dengan Proses Elektrokoagulasi (Atikah) 6-15

3. Penerapan Produksi Bersih Pada Industri Pulp dan Kertas. (Reno Fitrianti)... 1625

4. Studi Pengaruh Proses Pengintegrasian Panas Terhadap Konversi Amoniak Pada Intercooler Reaktor Amoniak Pusri II Dengan Analisis Pinch. (Desy Rosarina) 26-34

5. Pembuatan Biodiesel Dari Minyak Jelantah Dengan Variasi Penambahan Katalis KOH Pada Proses Transesteriikasi. (Muhrinsyah Fatimura, Daryanti, Santi). 3543

6. Evaluasi Kinerja Filter Keramik Pada Pengolahan Air Sungai Musi Berdasarkan Fluks Membrane. (Husnah). 44-49

7. Pengaruh Waktu Dan Massa Zat Asam Benzoate Terhadap Kadar Vitamin C Dalam Pembuatan Sirup Mangga. (Rully Masriantini) 50-55

Petunjuk Untuk Penulisan .$i i i$

Daftar Pustaka .$i v$ 


\title{
Petunjuk Untuk Penulis
}

\section{A. Naskah}

Naskah yang diajukan oleh penulis harus diketik dengan komputer menggunakan bahasa Indonesia yang baik dan benar, menyertakan 1 (satu) soft copy dalam bentuk CD. Penulisan memakai program Microsoft Word dengan ukuran kertas A4, jarak 1,15 spasi.

Naskah yang diajukan oleh penulis merupakan naskah asli yang belum pernah diterbitkan maupun sedang dalam proses pengajuan ditempat lain untuk diterbitkan, dan diajukan minimal 1 (satu) bulan sebelum penerbitan.

\section{B. Format Penulisan Artikel \\ Judul}

Judul ditulis dengan huruf besar, nama penulis tanpa gelar, mencantumkan instansi asal, email dan ditulis dengan huruf kecil menggunakan huruf Times new Roman 11.

\begin{abstract}
Abstrak
Abstrak ditulis dalam bahasa Indonesia antara 100-250 kata, dan berisi pernyataan yang terdapat dalam isi tulisan, menyatakan tujuan dari penelitian, prosedur dasar (pemilihan objek yang diteliti, metode pengamatan dan analisis), ringkasan isi dan kesimpulan dari naskah menggunakan huruf Time New Roman 11, spasi 1,15.

\section{Kata Kunci}

Minimal 3 (tiga) kata kunci ditulis dalam bahasa Indonesia

\section{Isi Naskah}

Naskah ditulis menggunakan huruf Times New Roman 11. Penulisan dibagi dalam 5 (lima) sub judul, yaitu Pendahuluan, Kajian Pustaka, Metode Penelitian, Hasil Pembahasan dan Kesimpulan. Penulis menggunakan standar Internasional (misal untuk satuan tidak menggunakan feet tetapi meter, menggunakan terminalogi dan simbol diakui international (Contoh hambatan menggunakan simbol R). Bila satuan diluar standar SI dibuat dalam kurung $($ misal $=1$ Feet $(\mathrm{m})$ ). Tidak menulis singkatan atau angka pada awal kalimat, tetapi ditulis dengan huruf secara lengkap, Angka yang dilanjutkan dengan simbol ditulis dengan angka Arab, misal 3cm, 4kg. Penulis harus secara jelas menunjukkan rujukan dan sumber rujukan secara jelas.
\end{abstract}

\section{Daftar Pustaka}

Rujukan / Daftar pustaka ditulis dalam urutan angka, tidak menurut alpabet, dengan ketentuan 
seperti dicontohkan sbb :

1. Standar Internasional :

IEC 60287-1-1 ed2.0; Electric cables - Calculation of the current rating - Part 1 - 1: Current rating equations (100\% load factor) and calculation of losses - General. Copyright (C) International Electrotechnical Commission (IEC) Geneva, Switzerland, www.iec.ch, 2006

2. Buku dan Publikasi :

George J Anders; Rating of Electric Power Cables in Unfavorable Thermal

Environment. IEEE Press, 445 Hoes Lane, Piscataway, NJ 08854, ISBN 0-471- 67909-7, 2005.

3. Internet :

Electropedia; The World's Online Electrotechnical Vocabulary.

http://www.electropedia.org, diakses 15 Maret, 2011.

Setiap pustaka harus dimasukkan dalam tulisan. Tabel dan gambar dibuat sesederhana mungkin. Kutipan pustaka harus diikuti dengan nama pengarang, tahun publikasi dan halaman kutipan yang diambil. Kutipan yang lebih dari 4 baris, diketik dengan spasi tunggal tanpa tanda petik. 


\title{
EVALUASI KINERJA FILTER KERAMIK PADA PENGOLAHAN AIR SUNGAI MUSI BERDASARKAN FLUKS MEMBRAN
}

\author{
Husnah \\ Dosen PNSD Program Studi Teknik Kimia Fakultas Teknik \\ Universitas PGRI Palembang \\ e-mail:husnahpgri@gmail.com
}

\begin{abstract}
ABSTRAK
Salah satu usaha untuk memperbaiki kualitas air Sungai Musi dari pencemaran yang terus meningkat yaitu dengan mentreatmentnya melalui proses filtrasi. Filter yang digunakan pada penelitian kali ini adalah jenis membran keramik. Proses filtrasi dilakukan dengan beda tekanan 32 psi dan 36 psi. Waktu pengambilan permeate dilakukan pada 15, 30, 45 dan 60 menit. valuasi kinerja membran keramik bisa dilihat dari nilai fluks yang dihitung berdasarkan volume permeate yang didapat per luas penampang membran. Nilai fluks terbaik adalah 2937,28 l/m².jam.
\end{abstract}

Kata kunci : Air Sungai Musi, Filtrasi, Membran keramik, Fluks membran

\section{PENDAHULUAN}

Air merupakan salah satu kebutuhan utama yang diperlukan manusia untuk menjaga kelangsungan hidupnya. Sumber-sumber air dapat digolongkan menjadi (Sutrisno, 2004) :

1. air laut

2. air permukaan

3. air atmosfer

4. air tanah

Salah satu sumber utama air yang digunakan untuk memenuhi kebutuhan hidup manusia, terutama di daerah pemukiman adalah air permukaan (air rawa dan air sungai). Di Sumatera Selatan sungai yang menjadi urat nadi kehidupan adalah Sungai Musi.

Peranan Sungai Musi sangat vital bagi masyarakat Sumatera Selatan khususnya warga kota Palembang, selain jalur transportasi dan wisata juga untuk memenuhi kebutuhan sehari-hari seperti mandi, cuci, bahkan minum. Umumnya masyarakat di pinggiran sungai Musi memanfaatkan air sungai ini secara langsung tanpa diolah terlebih dahulu, padahal jika dilihat secara langsung kondisi air di beberapa tempat di Sungai Musi saat ini cukup mengkhawatirkan terlihat dari kekeruhannya, bahkan di beberapa tempat berbau.

Karena air merupakan larutan yang hampir sangat universal, maka zat-zat yang paling alamiah maupun buatan hingga tingkat tertentu terlarut di dalamnya. Pencemaran air adalah peristiwa masuknya atau dimasukannya makhluk hidup, zat, energi, dan atau komponen lainnya kedalam air oleh kegiatan manusia, sehingga kualitas air turun sampai pada tingkat tertentu yang menyebabkan air tidak dapat berfungsi lagi sesuai peruntukannya (Peraturan Gubernur Sumsel No.18 thn 2005). Kualitas air yang terganggu ditandai dengan perubahan bau, rasa, dan warna. 
Hal-hal tersebut bisa merupakan indikasi bahwa air Sungai Musi sudah mulai tercemar, baik dari limbah domestik rumah tangga maupun dari limbah industri disekitar perairan Sungai Musi. Untuk penyediaan air bersih bagi warga kota Palembang dilakukan pihak PDAM kota Palembang dengan mengolah air Sungai Musi tersebut. Proses pengolahan yang umumnya dilakukan adalah proses pengolahan secara fisis, kimia dan biologi.

Secara fisis, pengolahan air biasanya melalui proses filtrasi (penyaringan) dan Sedimentasi (Pengendapan). Untuk membunuh mikroorganisme dalam air dilakukan pengolahan secara biologis dengan memberi disenfektan, sedangkan secara kimia dengan menambah zat kimia yang biasa disebut koagulan dan flokulan.

Agar air permukaan dapat dipergunakan sebagai sumber air bersih perlu dicari teknologi pengolahan air yang sesuai. Salah satu teknologi pengolahan air yang telah menjadi topik hangat dalam beberapa tahun terakhir ini adalah teknologi membran. Pemisahan dengan membran memiliki keunggulan diantaranya tidak membutuhkan zat kimia tambahan dan kebutuhan energinya sangat minimum. Membran dapat bertindak sebagai filter yang sangat spesifik. Hanya molekul-molekul dengan ukuran tertentu saja yang bisa melewati membran sedangkan sisanya akan tertahan di permukaan membran. Selain keunggulan-keunggulan yang telah disebutkan, teknologi membran ini semakin canggih, efisien, efektif, selektif, biaya kapital, operasi dan pemeliharaan sistem terus makin ditekan, murah, kompetitif dibanding cara-cara tradisional konvensional yang setara ( Hartono, 1997).

Pemisahan Membran yaitu suatu teknik pemisahan campuran 2 (dua) atau lebih komponen tanpa menggunakan panas. Komponen-komponen akan terpisah berdasarkan ukuran dan bentuknya, dengan bantuan tekanan dan selaput semi-permeable. Hasil pemisahan berupa retentate (bagian dari campuran yang tidak melewati membran) dan permeate (bagian dari campuran yang melewati membran).

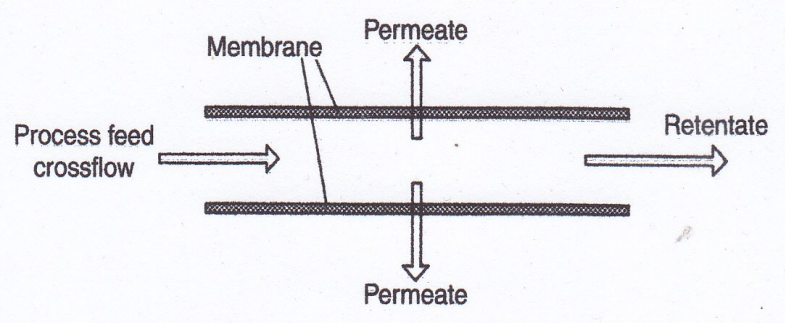

Gambar.1 Arah aliran dalam membran tipe cross flow

(Particle Technology and Separation Processes, Coulson and Richardson, 2002)

Konfigurasi dan ukuran membran dapat dibentuk sesuai dengan keperluan pada pemakaian. Beberapa konfigurasi membran :

1. lembaran datar ( plate and frame )

2. pipa ( tubular )

3. gulungan ( spiral wound)

4. serat berongga ( hollow fiber )

Jenis-Jenis Membran

1. Mikrofiltrasi ; Membran mikrofiltrasi berukuran 0.1-1.0 mikron untuk pemisahan partikel berukuran mikron atau semimikron. Bentuknya lazim berupa cartridge gunanya untuk menghilangkan partikel dari air yang berukuran 0.04-100 mikron. Filtrasi cartridge merupakan filtrasi mutlak, artinya partikel padat akan tertahan. 
2. Ultrafiltrasi ; pemisahan menggunakan membran untuk menghilangkan zat terlarut dengan bobot molekul tinggi, aneka koloid, mikroba sampai padatan tersuspensi dari larutan. biasanya digunakan di industri dan penelitian untuk penjernihan air karena ukuran yang dapat diolah adalah air pekat yang mengandung makromolekul yang memiliki berat atom 103-106 $\mathrm{Da}$ (1 $\mathrm{Da}=$ 0,000714 gram).

3. Nanofiltrasi ; proses pemisahan jika ultrafiltrasi dan mikrofiltrasi tidak dapat mengolah air seperti yang diharapkan. Pengolahan menggunakan nanofiltrasi umumnya menggunakan membran berukuran 0.0001-0.001 mikron. Nanofiltrasi cocok bagi air dengan total padatan terlarut yang rendah, dilunakkan dan dihilangkan senyawa organiknya.

4. Reverse Osmosis ; proses pengolahan yang membutuhkan tekanan relatif tinggi. Reverse osmosis didasarkan pada prinsip osmosis, adanya tekanan menyebabkan air melewati membran dari larutan konsentrasi rendah ke larutan dengan konsentrasi yang lebih tinggi. tekanan tersebut dinamakan tekanan osmosis.

Penelitian ini untuk mengolah air Sungai Musi yang terkontaminasi zat-zat polutan dari berbagai sumber menggunakan membran keramik dengan menganalisis pengaruh tekanan terhadap fluks.

\section{METODOLOGI PENELITIAN}

Pada percobaan ini filter keramik yang digunakan yaitu filter keramik komersial. Tahapantahapan penelitian yang dilakukan antara lain; tahap awal penelitian dengan penyiapan filter keramik. Tahap kedua adalah running alat dan tahap terakhir menghitung fluks membran. Hasil dari penelitian ini akan ditampilkan dalam bentuk tabel dan grafik.

Adapun lokasi-lokasi yang digunakan sebagai/tempat penelitian ini adalah : Lokasi pengambilan sampel air baku bertempat di Sungai Musi. Penelitian ini adalah skala laboratorium yang dilaksanakan di laboratorium Teknik Pemisahan Jurusan Teknik Kimia Fakultas Teknik Universitas Sriwijaya.

Alat dan bahan utama yang digunakan adalah: Filter keramik komersial, Flow meter, Selang plastik, Pressure gauge, Pipa PVC, Pompa, Gelas ukur dan gelas erlenmeyer, air sungai musi, pasir silika, karbon aktif.

- Skema Peralatan

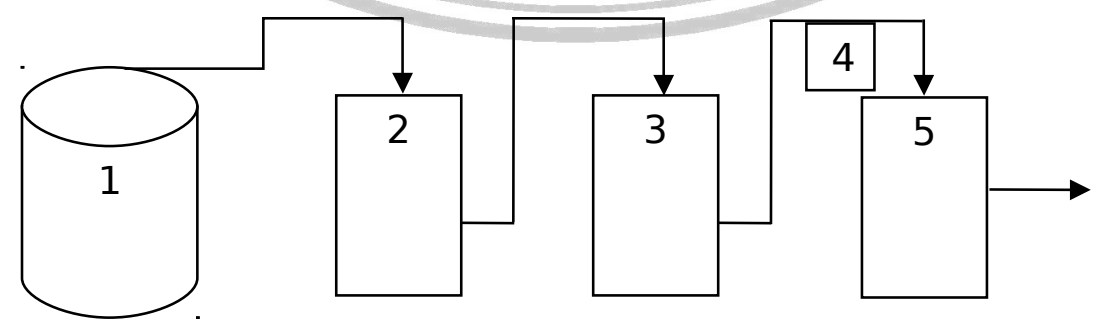

Gambar 2 : Rangkaian Alat Penelitian

1. Tangki Air 2. pasir silika 3. karbon aktiv 4. Pressure Gauge 5. Filter Keramik 


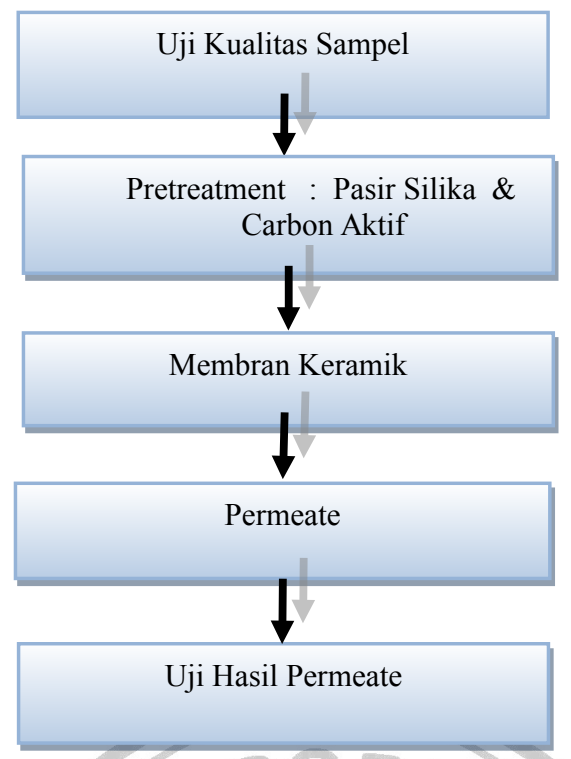

Gambar 3. Diagram alir proses

Pengambilan data dari sampel permeate utuk tiap-tiap filter untuk air baku yang berbeda dilakukan setiap 15, 30, 45 dan 60 menit.

\section{PEMBAHASAN}

Sampel awal air baku (air Sungai Musi) yang diambil pada bulan Juni 2013 dan dijadikan salah satu obyek penelitian memiliki kandungan seperti yang tertera pada tabel.1 dibawah ini:

\section{Tabel.1 Kandungan awal air baku}

\begin{tabular}{|l|c|c|c|}
\hline \multicolumn{1}{|c|}{ Parameter } & Satuan & Nilai Air Sungai & Max \\
\hline TSS & $\mathrm{mg} / \mathrm{L}$ & 18,2 & 50 \\
\hline Fe & $\mathrm{mg} / \mathrm{L}$ & $\mathbf{0 , 2 8}$ & $\mathbf{0 , 3}$ \\
\hline Minyak dan Lemak & $\mathrm{mg} / \mathrm{L}$ & 0,375 & 1 \\
\hline BOD $_{5}$ & $\mathrm{mg} / \mathrm{L}$ & 1,85 & 2 \\
\hline COD & $\mathrm{mg} / \mathrm{L}$ & 2 & 10 \\
\hline pH & - & 7,02 & $6-9$ \\
\hline EC & $\mu \mathrm{S} / \mathrm{cm}$ & 56,9 & - \\
\hline TDS & $\mathrm{mg} / \mathrm{L}$ & 29,4 & 1500 \\
\hline Turbidity & $\mathrm{NTU}$ & $\mathbf{7 0}$ & $\mathbf{2 5}$ \\
\hline
\end{tabular}

- Hubungan antara Fluks terhadap waktu operasi

Salah satu parameter untuk melihat kinerja dari membran adalah fluks yang merupakan ukuran kecepatan suatu spesi melewati membran persatuan luas dan waktu dengan gradient tekanan sebagai gaya dorong.

Fluks umunya dirumuskan sebagai berikut :

$$
J v=\frac{V}{A x t}
$$


Keterangan :

$$
\begin{array}{ll}
\mathrm{JV} & =\text { fluks } \\
\mathrm{V} & =\text { volume permeat }(\mathrm{ml}) \\
\mathrm{A} & =\text { Luas permukaan membran }\left(\mathrm{cm}^{2}\right) \\
\mathrm{t} & =\text { waktu }(\text { det })
\end{array}
$$

Pada penelitian ini volume permeat yang dihasilkan pada tiap tekanan (32 dan 36 psi) dengan variasi waktu $(15,30,45$ dan 60 menit) diamati sehingga nilai fluks pada tekanan dan waktu tersebut dapat diketahui melalui perhitungan menggunakan persamaan untuk fluks. Tabel dan grafik dibawah ini menggambarkan pengaruh waktu operasi terhadap fluks dari Membran Keramik Komersial untuk air Sungai.

Tabel 2. Fluks permeate

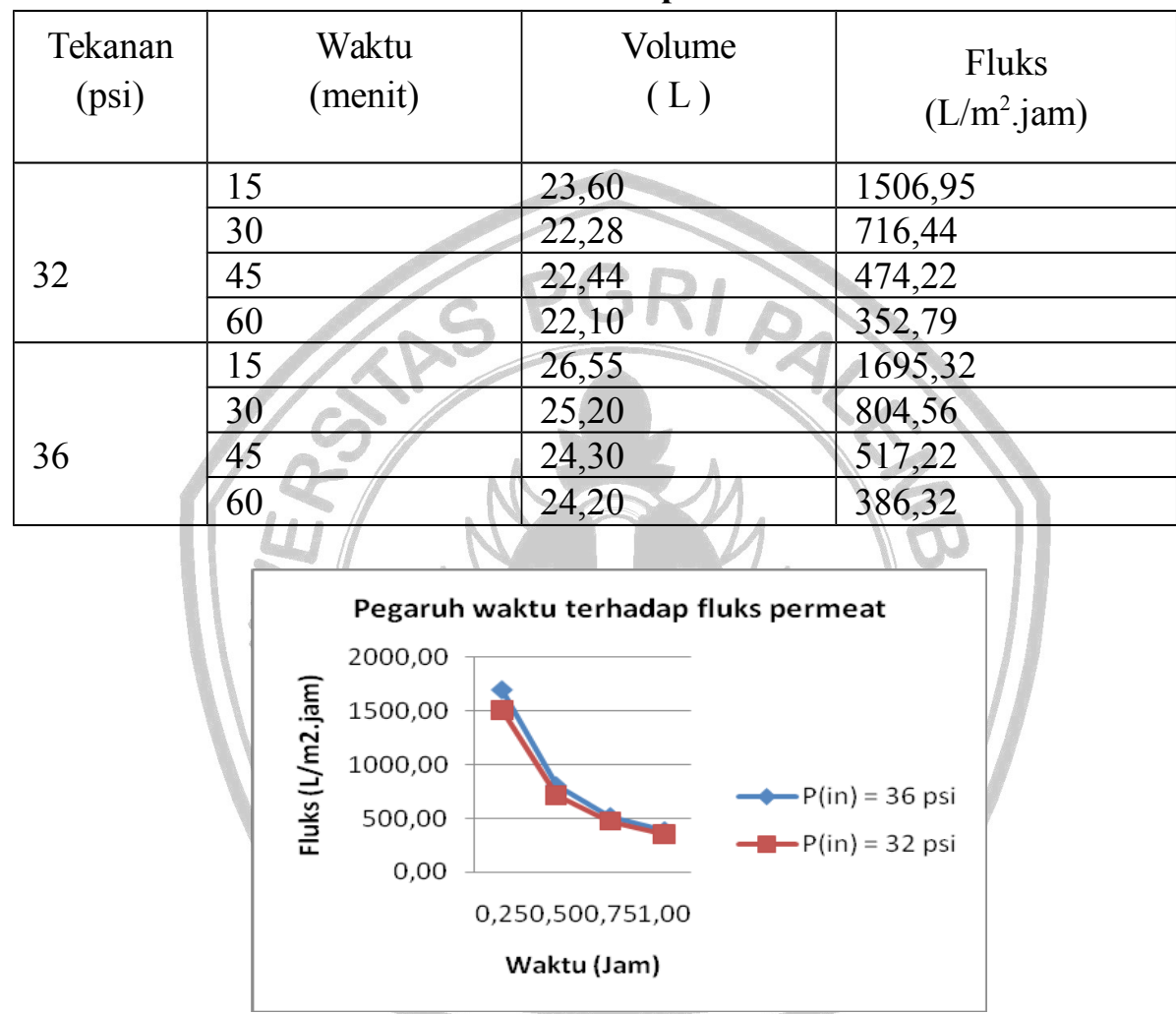

\section{Gambar 4. Pengaruh waktu operasi dan tekanan terhadap fluks}

Dari grafik fluks terhadap waktu operasi di atas terlihat dengan bertambahnya waktu terjadi penurunan fluks yang berarti bahwa adanya penurunan kinerja membran. Hal ini bisa diakibatkan adanya fouling sepanjang proses operasi filtrasi air baku, diantaranya akibat pengendapan dari padatan yang mungkin masih terlarut dalam air baku dan lolos pada permukaan membran sehingga menutup sebagian pori-pori membran.

Beberapa hal yang bisa dilakukan untuk menghindari fouling antara lain ; perlakuan awal larutan, mengubah sifat membran, pengaturan kondisi operasi, dan pembersihan membran. Dari grafik tersebut terlihat juga bahwa kenaikan tekanan berpengaruh terhadap kenaikan volume permeat sehingga fluks juga meningkat. 


\section{KESIMPULAN}

1. Perbedaan tekanan operasi mempengaruhi kinerja membran keramik. Semakin besar perbedaan tekanan semakin besar fluks membran. Pada penelitian ini kinerja fluks terbaik dicapai pada tekanan 36 psi .

2. Nilai fluks terbesar dicapai pada membran keramik untuk air sungai $=2937,28 \mathrm{~L} / \mathrm{m}^{2}$.jam.

\section{SARAN}

1. Perlu dilakukan penelitian lebih lanjut terhadap pengolahan air menggunakan membran keramik agar kinerjanya lebih baik terutama untuk meningkatkan selektifitasnya.

2. Perlu dilakukan analisis terhadap kuat tekan membran keramik sehingga dapat diketahui ketangguhan dari membran.

\section{DAFTAR PUSTAKA}

Hartono, A.J, (1994). Teknologi Membran Pemurnian Air. Edisi 1. Yogyakarta.

Sutrisno, T (2004). Teknologi Penyediaan Air Bersih. Rineka Cipta, Jakarta.

Richardson, J.F and Coulson (2002). Particle Technology and Separation Processes. Volume 2, Fifth Edition, Elsevier.

(2005). Peraturan Gubernur Sumatera Selatan No 18 tahun 2005 tentang Baku Mutu Limbah Cair (BMLC) bagi Kegiatan Industri, Hotel, Rumah Sakit, Domestik dan Pertambangan.

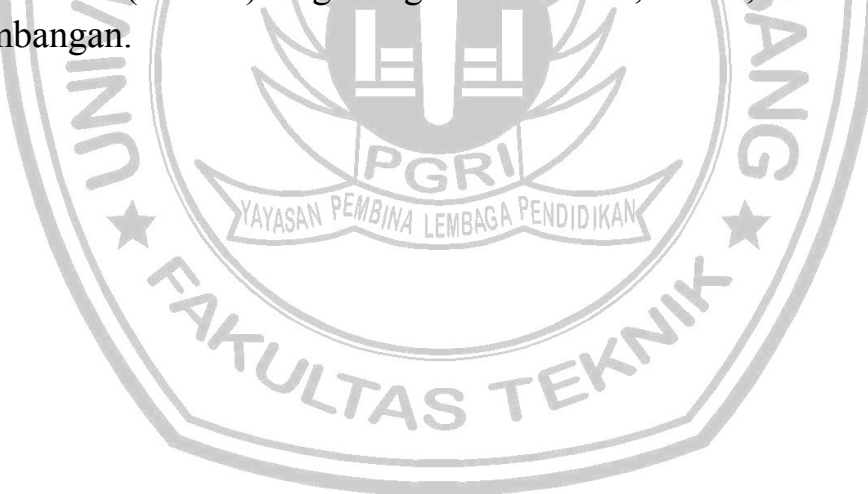

